\title{
Study of Oil Content in Fruits of Wild Olive (Olea caspidata Wall.Ex G.Don) and Its Potential Commercialization in Nepal
}

\author{
Netra Lal Bhandari ${ }^{1 *}$, Krishna Bahadur Kunwar Chhetri ${ }^{2}$, Durga Prasad Pandey ${ }^{3}$, Kanchan Kumar \\ Nayak $^{4}$ \\ ${ }^{I}$ Department of Chemistry, Tri-Chandra Multiple Campus, Tribhuvan University, Kathmandu, Nepal \\ ${ }^{2}$ Kathmandu Forestry College, Institute of Forestry, Tribhuvan University, Kathmandu, Nepal \\ ${ }^{3}$ Research Center for Applied Science and Technology, Tribhuvan University, Kathmandu, Nepal \\ ${ }^{4}$ Department of Food Technology and Quality Control, Kathmandu, Nepal \\ Email:nlbhandari@yahoo.com
}

\begin{abstract}
This study was aimed to measure some of the basic chemical parameters to analyze the oil content in the seeds of wild olive (Olea cuspidata) fruits collected from the Jagannnath/Kotila and Wai forests of the Bajura district of Nepal. The oil was obtained by solvent extraction process using soxhlet and analyzed by various techniques. The oil content in fruits was found to be $24.3 \mathrm{wt.-} \%$ of the total dry fruit mass. The refractive index, saponification, iodine, acid and peroxide values in the extracted oil were found to be comparable with the standard reported values. The results so far obtained hints on high feasibility for commercial cultivation of olives in the Bajura district provided that the proper management measures are undertaken.
\end{abstract}

Keywords: Olive oil, refractive index, saponification value

\section{Introduction}

Olives named as Jaitoon in Sanskrit, Arabic, Hindi, and Nepali is the evergreen trees native to the mediterranean region. It is found naturally in Bajura, Dolpa, Rukum, Humla Bajhang and Mugu districts of Nepal ${ }^{1,2}$. Different species of olives are found in Nepal. The Olea cuspidata is a species locally known as Lotto in Dolpa and Launtho in Bajura districts of Nepal and Kahu in Himachal (Jammu \& Kashmir) and Uttar Pradesh of India ${ }^{3,4}$. Olive belongs to the taxonomical order, Liguustrales and family Oleaceae. The common olive is botanically called Olea europaea var. sativa which is the most cultivated olive tree in the world whereas Olea cuspidata (sub-species of europaea), is a wild species found in forest of our subcontinent and also in $\mathrm{Nepal}^{3-5}$. Olea which has an auto regeneration capacity falls under the regime of threatened plants in Nepal and kept under the rare category in the Red Data Book of International Union for Nature Conservation (IUCN) ${ }^{6,7}$. This species has not been comprehensively studied in terms of geographical distribution in Nepal ${ }^{7-10}$.

In Nepal, wild olives were first recorded as Matyalo of Bajura district on both the deforested and cultivated areas along the Karnali River since 1965. According to the literature it has been supposed to be introduced several times in Nepal from India, Israel, Italy, France, Spain, Syria \& Egypt ${ }^{1,11}$. The olive

\footnotetext{
* Corresponding author
} 


\section{J. Nepal Chem. Soc., Vol. 36, 2017}

seedlings were planted in Godavari area of Lalitpur, Chitlang area of Makawanpur, Kritipur Horticulture Center, Juphal of Dolpa, Ghasa of Mustang and District Agricultural Development Office of Dadeldhura 2-4,12. For plant multiplication, a small breeding unit has been built at Godavari to supply olive saplings to mid-hill districts of Western Development Regions. A study conducted on the distribution pattern of olive in Bajura district of Nepal revealed that the status of wild olive has conspicuous potentiality for the further promotion ${ }^{4,5}$.

Recently, several commercial private olive orchards have been practiced in Chitlang (Makawanpur), Kolti and Wai (Bajura), Jhuphal (Dolpa) and Kirtipur (Kathmandu), which are supported by the Food and Agriculture Organization (FAO) project under 'Promotion of olive production and consumption in Nepal' and financed by Italian Ministry of Foreign Affairs ${ }^{1,13}$. In Nepal 35 forest, types have been identified and Olea recorded under Trans-Himalaya High Alpine Vegetation but not included under any forest classification ${ }^{12}$. However, in Medicinal Plants of Nepal published by Department of Plant Resources (DPR) in 2007, the olive distribution range has been listed from 500-2600 masl in the Trans-Himalayan region but especially document listed Kaligod, Kolti and Boldhik locality of Bajura district at 2192 masl as the best site of olive distribution in Nepal ${ }^{1-3,14}$. Nepal has just been in initial stage for cultivation and domestication of some programs involved in Olive Program in Nepal. They have introduced olive plantation in some parts of the country (Nepal) to give some aspiration for the future.

The percentage oil and chemical constituent play key role in standard quality determination of olive products (olive oil). This study explored some ideas to take decision on olive promotion in Nepal in the commercial scale. The importance of olive plants is to produce high quality oil, which is used for cooking oil, cosmetics, pharmaceuticals, soap, body massage \& better result in different human disease throughout the world ${ }^{3,14}$. However, the very basic systematic documentation of plant species \& their chemical constituents has not been done yet in Nepal ${ }^{15}$. In this work, Karnali and their watershed/micro-climate areas of the Bajura district elevating from 762-2600 masl was considered as study sites and fruits were collected from boarder sides of Jaganath/Kotila and Wai forests of the district. The well ripened fruits were obtained in October/November. In January/February the plant becomes physiologically matured for the next cycle ${ }^{4,5}$. An olive fruit consists of three basic parts; the skin (epicarp), the pulp (mesocarp), and the stone or pit (endocarp) where oil is present in all parts but highest content of oil about $50 \%$ is in the pulp, which represents about 75 wt.- $\%$ of the total fruit mass. Oil content in olive fruit also depends on the species variety of plant, its maturity and efficiency of extraction. Different grades of oil are extracted by various techniques. The purest form of oil the extra virgin and refined grade oils are obtained by cold pressing whereas the lower grades and pomace oil are extracted by solvent extraction from the residue left after the cold pressing. ${ }^{3,14-16}$

With the increase in World population for the consumption of oil its production is also increasing day by day. Production \& transaction of olive oil was 2.9 million tons in 2009 over the world. Production system adapted range from big commercial plantation to individual farmers. Italy, Spain and Greece are the countries with the major oil exporter as well as consumer countries. In Asia, olive oil consumption \& production is not yet as noticeable but in India, China and Pakistan it has already been in practice. India imported 1,500 tons of olive oil in 2006, 2,300 tons in 2007, and 4,500 tons in 2008, and in 2012, the demand will be close to 42,000 tones. Nepal has also imported 5000 liters of olive oil annually of olive oil from Europe ${ }^{13-17}$. Already from 1990, the worldwide consumption of olive oil doubled and expected as 
triple between 2000 and 2020. However, the very basic systematic documentation of plant species $\&$ their chemical constituents has not been done till yet in Nepal.

The main objective of this study is to review and analyze the oil obtained from the wild olive Olea caspidata fruits collected from Jaganath/Kotila and Wai forest of Bajura district in October 2010 and also explore the knowhow for the potential feasibility of its commercialization.

\section{Experimental Methods}

\section{Sample Collection}

Dry and mature fruits of wild olive Olea caspidata were collected by handpicking from Jaganath/Kotila and Wai forest of Bajura district of Nepal in October 2010.

\section{Oil extraction}

The fruits were dried in shade for 10 days at $25 \pm 2{ }^{\circ} \mathrm{C}$ followed by grinding to powder by iron pestle in the laboratory. 600 gram powder was wrapped in a cellulose paper and packed inside a three liter soxhlet fitted with condenser. The extraction was carried out at $60^{\circ} \mathrm{C}$ for 8 hours following the standard procedure of AOAC, 1984, for three days using petroleum ether as solvent. Finally, the solvent was evaporated by using rotary evaporator and the oil was separated and collected in a conical flask. The weight of fresh fruits, dried fruits and the extracted oil from olive was measured.

\section{Analysis of basic chemical parameters of extracted oil}

The extracted oil was analyzed at Department of Food Technology and Quality Control (DFTQC), Kathmandu according to the standard protocol described in the manual. Refractive index (RI), saponification value (SV), iodine value (IV), acid value (AV) and peroxide value (PV) were measured.

\section{Results and Discussion}

The average oil content in the fruits of the wild olive (Olea cuspidata) collected from Bajura district of Nepal has been found to be 24.3 wt.- $\%$ of the total dry fruit mass which is much better than that reported in Kenyan species (6.4 wt.- \%) and near close to that of the Pakistani species (32.7 wt.- $\%)^{[14-16]}$. The percentage yield of oil from dry olive fruits collected from Nepal is encouraging to that of the olive collected from other countries. Table 1 shows the estimated economic value of commercialization of olive oil production in Bajura district.

Table 1: Annual yield of existing olive oil in Jaganath and Wai forests, in most potential sites in different village development committees of Bajura district, and in well managed orchard ${ }^{[14]}$.

\begin{tabular}{|l|l|l|l|l|l|l|l|l|}
\hline $\begin{array}{c}\text { Forest } \\
\text { Name }\end{array}$ & $\begin{array}{l}\text { Area in } \\
\text { hector }\end{array}$ & $\begin{array}{c}\text { Total } \\
\text { trees/ } \\
\text { hector }\end{array}$ & $\begin{array}{c}\text { Fruits } \\
\text { in kg } \\
\text { /tree }\end{array}$ & $\begin{array}{c}\text { Fresh } \\
\text { fruit } \\
\text { mass (kg) }\end{array}$ & $\begin{array}{l}\text { Dry fruit } \\
\text { mass (kg) }\end{array}$ & $\begin{array}{c}\text { Estimated } \\
\text { oil (kg) }\end{array}$ & $\begin{array}{c}\text { Rate } \\
\text { /kg } \\
\text { (NRs) }\end{array}$ & $\begin{array}{c}\text { Total } \\
\text { NRs. } \\
\text { million }\end{array}$ \\
\hline $\begin{array}{l}\text { Jagannath/ } \\
\text { Kotila } \\
\text { forest }\end{array}$ & 80.4 & 200 & - & 4162 & 2205 & 523 & 2000 & 1.0458 \\
\hline Wai forest & 118.6 & 255 & - & 14927 & 7911 & 1874 & 2000 & 3.7480 \\
\hline Total & $\mathbf{1 9 9}$ & & - & $\mathbf{1 9 0 8 8}$ & $\mathbf{1 0 1 1 6}$ & $\mathbf{2 3 9 7}$ & & $\mathbf{4 . 7 9 3 8}$ \\
\hline
\end{tabular}




\begin{tabular}{|l|l|l|l|l|l|l|l|l|}
\hline $\begin{array}{l}\text { Potential } \\
\text { sites in six } \\
\text { VDCs }\end{array}$ & 5845 & 200 & - & 993650 & 526634 & 124812 & 2000 & $\begin{array}{l}249.62 \\
40\end{array}$ \\
\hline $\begin{array}{l}\text { Estimated } \\
\text { yield in well } \\
\text { managed } \\
\text { orchard per } \\
\text { hector }\end{array}$ & - & 333 & 100 & 33300 & 17649 & 4183 & 2000 & 8.3660 \\
\hline
\end{tabular}

It has been clear that the two forests (Jaganath/Kotila \& Wai) can contribute NRs 4.79 million per annum whereas the most potential sites under six Village Development Committees such as Wai, Jagannath, Kotila, Kolti, Sapata, Bhandu, Gotri, Rugin \& Jukot forests of Bajura district can contribute total NRs 249.6 million per annum from wild olive fruits. Hence, Bajura is potentially very important area for the cultivation and production of olive. The present status of estimated quantity of olive production in Jaganath/Kotila and Wai forests has also been expressed as a bar diagram in Figure 1.

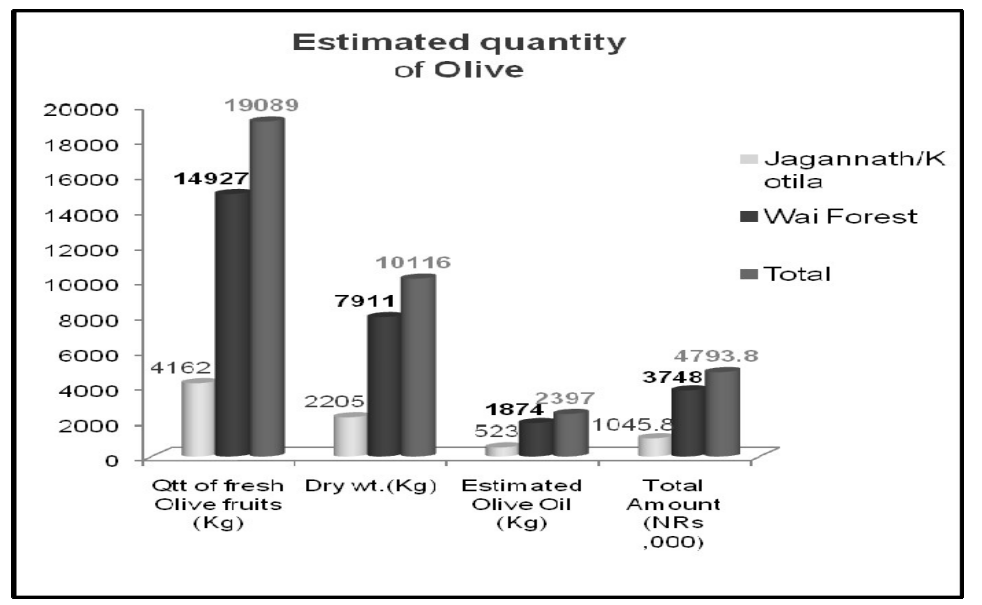

Figure 1: Present status of estimated quantity of olives in Jaganth/Kotila and Wai forests 14.

These results show that olive plantation and cultivation would play a key role in the economy of the country. After commercializing the olive production in hilly regions can provide employment opportunities in the bare hilly mountains which are unsuitable for the other crops as well as helps for soil conservation by reducing problem of environmental degradation and deforestation. Further, Bajura district is one of the most potential areas (estimated to about NRs. 8.36 million per hector) for the olive promotion and production due to records of wild olive in wild form in significant quantity. These facts motivate to commercialize olive production in those areas that can battle against the food security since several decades.

Further the five very basic parameters of the extracted olive oil such as the refractive index, saponification, iodine, acid and peroxide values were measured, and results are presented in Table 2. It shows that, the refractive index value (1.46), saponification value (191.29 $\mathrm{mg} \mathrm{KOH} / \mathrm{g}$ oil) and iodine value (82.66) of olive oil samples were found to be within the range prescribed by the national DFTQC and international IOOC standards for the olive oil for human consumption. 
Table 2: Values of five basic parameters in extracted olive oil compared to the IOOC and DFTQC standards.

\begin{tabular}{|l|l|l|c|c|c|}
\hline S.N. & Parameters & \multicolumn{1}{|c|}{ Unit } & $\begin{array}{c}\text { Sample } \\
\text { olive oil }\end{array}$ & IOOC standard & DFTQC standard \\
\hline 1 & $\begin{array}{l}\text { Refractive } \\
\text { index }\end{array}$ & & 1.46 & $1.46-1.4705$ & $1.4601-1.4630$ \\
\hline 2 & $\begin{array}{l}\text { Saponification } \\
\text { Value }\end{array}$ & mgKOH/gm oil & 191.29 & $184-196$ & $184-196$ \\
\hline 3 & Iodine value & Wijs & 82.66 & $75-94$ & $75-94$ \\
\hline 4 & Acid Value & mgKOH/gm oil & 13.97 & 6.6 & 6.0 \\
\hline 5 & $\begin{array}{l}\text { Peroxide } \\
\text { value }\end{array}$ & m.eq/kg oil & 38.91 & 20 & 20 \\
\hline
\end{tabular}

$\mathrm{IOOC}=$ International Olive Oil Council

DFTQC $=$ Department of Food Technology and Quality Control

The saponification value of the olive oil was found to be almost similar to that of the sunflower oil and linseed oil where as the iodine value of it is much lower than others ${ }^{[17,18]}$. It indicates that the molecular weight of the extracted olive oil was similar to that of the sunflower oil and the linseed oil but it was more saturated (containing more saturated fatty acids) than the others. Figure 2 also represents the bar diagram for five basic parameters of olive in extracted oil compared to IOOC and DFTQ standards.

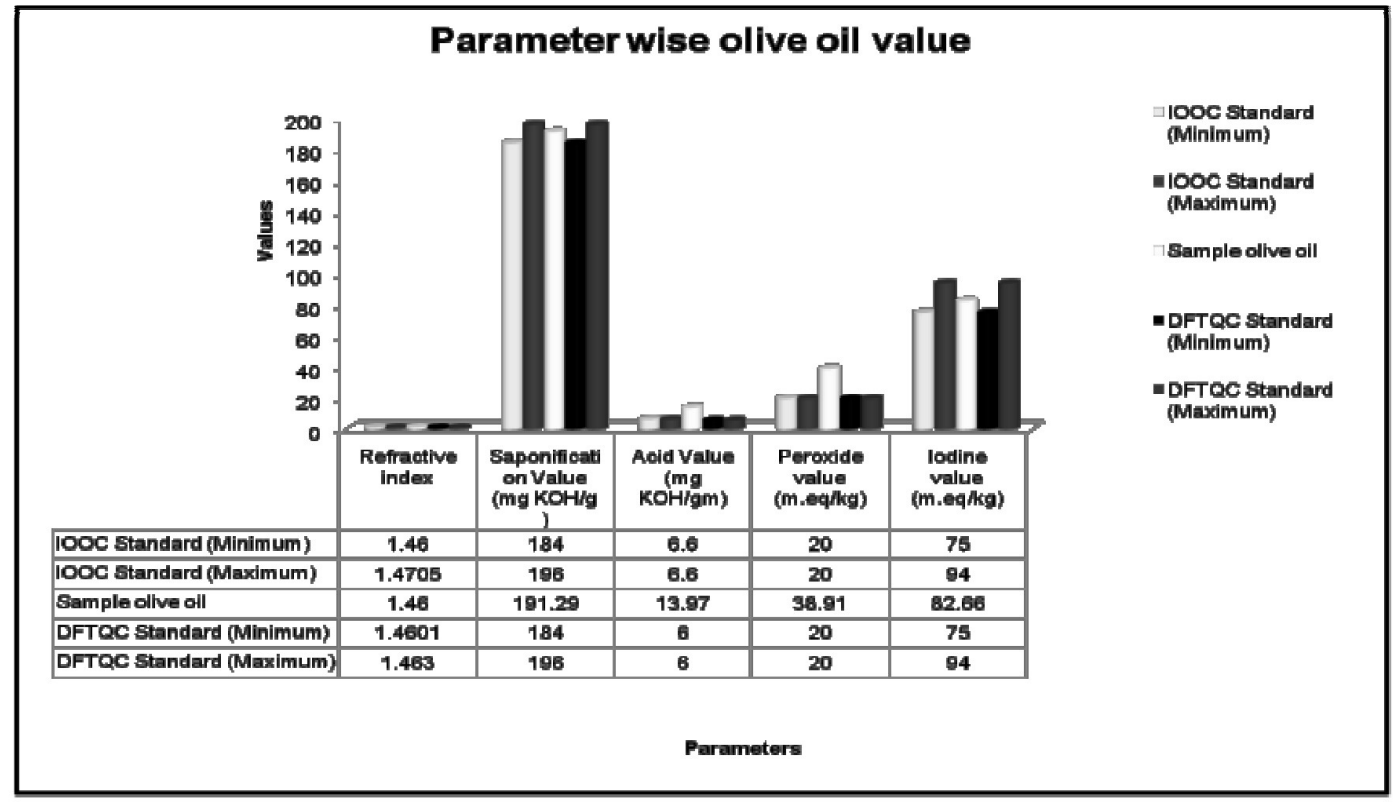

Figure 2: Five basic parameters of olive in extracted oil compared to the IOOC and DFTQC standards.

Furthermore, the acidity (13.97) and the peroxide value (38.91) of the extracted oil were found to be higher than the national and international standard values. It might be the results of oxidation. Light and

$-5-$ 


\section{J. Nepal Chem. Soc., Vol. 36, 2017}

the oxygen are the two main factors for the oxidation after harvesting. The literatures study also suggest to store the fruits at very low temperature below $2-3^{\circ} \mathrm{C}$ then it can be stored safely for about one month otherwise it should be pressed within the 24 hours of harvesting to reduce the acidity. It has not been studied till yet and would be the area for the further analysis and study.

Olive oils are distinct from other vegetable oils because they may be consumed without extensive refining. Free Fatty acid (FFA) of an olive oil can be used as a measure of its quality. In refined vegetable oils, the lower the FFA the more acceptable for the human consumption. Virgin olive oils cannot be categorized in this way because their characteristics flavor involves a sharp component that results from the FFA present. Therefore, a higher FFA is acceptable in virgin olive oil than the refined one.

\section{Conclusions}

From this research study it can be concluded that the oil content in the wild olive fruits collected from Bajura district is in considerably encouraging amount as compared with the other countries. Thus research area is potentially important for the cultivation and production of olives. The results push to move further promotion and commercialization of olive. It would be one of the alternatives to battle against food scarcity partially for the local people by compensating income from olive enterprise in future because on proper management the olive can contribute an income of NRs. 8.4 million per annum per hector of olive trees from Bajura district. These pictures present the good scenario for the further promotion of olivebased enterprise in the district. The extracted oil from the wild olive requires further verification mainly in its acidity and peroxide value before recommendation for the public consumption but it has a fairly good range of refractive index as well as saponification and the iodine values.

\section{Acknowledgements}

The authors would like to thank Kathmandu Forestry College (KAFCOL), Kathmandu for providing financial support to K. B. K. Chhetri for the research. Thanks also go to Department of Plant Resources, Kathmandu and Department of Food Technology and Quality Control (DFTQC), Kathmandu for providing laboratory and technical support for the analysis of chemical parameters in olive oil.

\section{References}

1. P. Bartolucci, and B. R. Dhakal, Prospects for Olive Growing in Nepal, His Majesty's Government Department of Agriculture, Fruit Development Division Olive Production Development Project, TCP/NEP/6713 and Food and Agriculture Organization of the United Nations, Kathmandu, 1999.

2. District profile, Central Bureau of Statistic (CBS), District Office, Martadhi, Bajura, 2009.

3. Annual Report, Indian Olive Association, 2009.

4. B. R. Dhakal and Regmi a. Jaitoon (Nepali version), Promotion of olive production and consumption in Nepal, Kathmandu, Nepal, 2009.

5. Report, District Forest Office (DFO), Martadi, Bajura, 2008/09.

6. S. B. Malla, P. R. Shakya, B. R. Karki, T. R Mortensen and N. R. Subedhi, A study on non-timber forest products in Bajura district volume I (main report), Care-Nepal, Kathmandu, Nepal, 1999.

7. T. B. Shrestha and R. M. Joshi, Rare, endemic and endangered plants of Nepal, WWF/Nepal Program, Kathmandu, Nepal, 1996. 
8. G. M. Balestra, J. R Lamichhane, M. B. Kshetri, A. Mazzaglia and L. Varvaro Plant Pathology, 2009, 58, 393.

9. W. E. Bull, The olive industry of Spain, Econ. Geogr, 1936, 12, 136.

10. W. B. Turill, Wild and cultivated olives, Kew Bulletin, 1951, 3, 339.

11. D. Zohary, The origin and spread of cultivated plants in West Asia, Europe and the Nile Valley, Clarendon Press, Oxford, 1993.

12. WWF-Strategic Plan (2006-2011), World Wildlife Fund, (WWF/Nepal), Kathmandu, Nepal, 2006.

13. Medicinal plants of Nepal (Revised.), Department of Plant Resources (DPR), Bulletin of the Department of Plant Resource No. 28, Kathmandu, Nepal, 2007.

14. K. B. K. Chhetri, Analysis of oil content and some of the physical and chemical parameters in wild Olive fruits found in Bajura district of Nepal, B. Sc. Forestry, Thesis, 2011.

15. M. Gulfraz, Determination of essential oil content of wild olive and its comparision with olive oil, 2006.

16. K. Murwan, E. L. Sabah and A. S. A. Alamin, The compositional quality of six refined edible oils in Khartoum State, Sudan, 2009.

17. N. Ouazzani, R. Lumaret, P. Viuemur and F. Di Guito, Leaf alloenzyme variation in cultivated and wild olive trees. Journal of Hared, 1993, 84, 34.

18. A. Bahl and B. S. Bahl, A text book of organic chemistry, S. Chanda and Company LTD., New Delhi, India, 2006, 534. 